\title{
Chromosome variability in the Chagas disease vector Rhodnius pallescens (Hemiptera, Reduviidae, Rhodniini)
}

\author{
Andrés Gómez-Palacio, Nicolás Jaramillo-Ocampo, Omar Triana-Chávez, Azael Saldaña1, \\ José Calzada1', Ruben Pérez², Francisco Panzera²/+
}

\begin{abstract}
Grupo de Chagas, Sede de Investigación Universitaria (SIU), Instituto de Biología, Universidad de Antioquia, Medellín, Colombia ${ }^{1}$ Instituto Conmemorativo Gorgas de Estudios de la Salud (ICGES), Panama City, Panama ${ }^{2}$ Sección Genética Evolutiva, Facultad de Ciencias, Universidad de la República, Calle Iguá 4225, CP 11400 Montevideo, Uruguay
\end{abstract}

Rhodnius pallescens is the main vector of Trypanosoma cruzi in Panama and one of the most relevant secondary vectors in Colombia. Despite the importance of this species, there is limited knowledge about the genetic variability along its geographical distribution. In order to evaluate the degree of karyotype variability we analyzed the meiotic behavior and banding pattern of the chromosomes of 112 males of $\mathrm{R}$. pallescens coming from different regions of Colombia and Panama. Using the C-banding technique we identified two chromosomal patterns or cytotypes characterized by differences in the amount, size and distribution of constitutive heterochromatic regions in the chromosome complement $(2 n=20$ autosomes plus XY in males). The individuals can be easily classified in each cytotype by the analysis of the chromosomes during first meiotic prophase. The frequencies of the cytotypes are variable according to the geographic origin of the populations. This chromosomal divergence together with morphological data supports the existence of three genetically different populations of $\mathrm{R}$. pallescens and provides new information to understand the distribution dynamics of this species.

Key words: Triatominae - Rhodnius pallescens - intraspecific variation - cytogenetics - chromosome variation - Chagas disease

The Triatominae (Hemiptera, Reduviidae) includes 137 species of haematophagous true bugs customarily grouped into six tribes and 19 genera (Galvão et al. 2003). These insects are widely distributed in the American continent, where they have medical importance as vectors for the parasitic agent of Chagas disease, Trypanosoma cruzi. Rhodnius pallescens is an important vector of T. cruzi in Panama, and has also been reported from Belize, Colombia, Costa Rica, and Nicaragua (Zeledón et al. 2006). There is also an unconfirmed report of its occurrence in the Amazonian region of Venezuela (Ramírez-Pérez 1987).

This species is mainly sylvatic and inhabits nests of marsupials and small mammals located in different species of palms (Christensen et al. 1980, Christensen \& de Vasquez 1981, Jaramillo et al. 2000). Nevertheless, the synanthropic intervention in its natural habitat has increased the maninsect contact, which is reflected in the frequent events of intrusion of adult bugs into human dwellings. This occurs in Costa Rica (Marín \& Vargas 1986, Ponce 2007) and mainly in Panama where $R$. pallescens is the main vector of Chagas disease (de Vasquez et al. 2004, Calzada et al. 2006, Zeledón et al. 2006).

Accurate information on the population structure and dispersal potential of triatomine species is essen-

\footnotetext{
Financial Support: ECLAT network, CSIC and PEDECIBA from Uruguay, European Community (Project Contract N ${ }^{\circ}$ CDIA-ICA4CT-2003-10049 and ATU-SSA-CT-2004-515942) and by CODI of the Universidad de Antioquia, Medellín, Colombia (project: CPT-0604). + Corresponding author: panzera@fcien.edu.uy

Received 22 August 2007

Accepted 18 February 2008
}

tial for the design of effective vector control strategies. Aiming in that direction, the genetic variability of $R$. pallescens populations has been studied using different approaches. Isoenzymatic analysis of two populations of $R$. pallescens from Colombia showed a reduced average heterozygosity $(\mathrm{H}=0.0005)$ indicative of a low genetic variability (López \& Moreno 1995). The isolation and characterization of ten microsatellite loci identified between 2 and 20 alleles in a single population of $R$. pallescens from the Colombian Caribbean region (Harry et al. 1998). This apparently high genetic variability was also supported by the identification of four different haplotypes in the mitochondrial cytochrome b (mt cyt b) gene of nine individuals of $R$. pallescens from Colombia and Nicaragua (Abad-Franch 2003).

Cytogenetic analysis has been used to characterize more than 70 species of Triatominae (Dujardin et al. 2002) and to describe chromosome variability in some species with great epidemiological importance such as Triatoma infestans (Panzera et al. 2004) and Triatoma dimidiata (Panzera et al. 2006). Chromosomal variation in triatomines mainly involves changes in the amount, disposition and behavior of constitutive heterochromatin. These highly condensed chromatin regions usually comprise dispersed repeated DNA sequences (mobile genetic elements or transposons) and satellite DNA (Gregory 2005).

Few data exist about the cytogenetic characteristics of $R$. pallescens (Panzera et al. 1996, 1998). It has a diploid number of 22 chromosomes (20 autosomes plus 2 sex chromosomes, $\mathrm{XY}$ in males and $\mathrm{XX}$ in females). C-banding technique detected heterochromatic regions in one or both ends of some autosomes and in most part of the Y chromosome (Panzera et al. 1998), but these 
studies were limited to a few individuals from a laboratory colony, and did not involve comparisons with fieldcollected specimens. In the present paper we evaluate the chromosomal variability in $R$. pallescens by the analysis of 112 specimens belonging to 12 natural populations from Colombia and one population from Panama.

\section{MATERIALS AND METHODS}

Insects - A total number of 112 males of $R$. pallescens was analyzed. Most of them (81) were field-collected, mainly from Attalea butyracea and Elaeis oleifera palm trees, and the rest were drawn from laboratory colonies established with specimens of known origin by the Chagas group of the "Universidad de Antioquia" in Medellín, Colombia. Details on the origin and number of individuals are shown in Table and Fig.1.

Cytogenetic studies - Testes were removed from freshly killed adults, fixed in an ethanol-acetic acid mixture $(3: 1)$ and stored at $-20^{\circ} \mathrm{C}$. Air-dried chromosome preparations were made by squashing gonads in $50 \%$ acetic acid, freezing them in liquid nitrogen and removing the cover slip with a razor blade. The $\mathrm{C}$-banding technique was performed following Pérez et al. (1997) in order to examine the distribution and behavior of Cheterochromatin during mitosis and meiosis. The pattern of C-banding for each individual was determined from analysis of at least 50 mitotic cells (prometaphase) and meiotic cells (metaphase I and II). For comparing the populations we analyzed the size and the number of chromosomes showing constitutive heterochromatin and the behavior and distribution of the heterochromatin regions during meiosis in autosomes and in sex chromosomes (Panzera et al. 1995, 1997, 2004, Pérez et al. 1997, 2002). Observations were carried out with a Nikon Microphot FX microscope (Nikon, Tokyo, Japan). Chromosome images were obtained using Ilford 50 film (Ilford Ltd, Cheshire, UK).

\section{RESULTS}

Chromosome complement - All specimens analyzed showed the same diploid chromosome number $(2 n=22)$ constituted by 20 autosomes and a pair of sex chromosomes (XY) (Figs 2A, B). As typical for triatomines, the chromosomes were holocentric (i.e. without a localized centromere). The autosomes exhibited little size variation while the $\mathrm{X}$ and $\mathrm{Y}$ chromosomes were the smallest and had similar sizes (Figs 2A, B).

Behavior and C-banding pattern of the sex chromosomes - As generally observed in Hemiptera, the sex chromosomes of $R$. pallescens are achiasmatic and behave as univalents (unpaired chromosomes) during first meiotic division. However, they usually appear associated during the meiotic prophase, forming a single heterochromatic chromocenter (Figs $3 \mathrm{~A}-\mathrm{C}$ and $3 \mathrm{E}-\mathrm{G}$ ). The C-banding pattern of the sex chromosomes was clearly observed from early meiotic prophase to diplotene, when the chromatin was not yet fully condensed. The Y chromosome exhibited heterochromatic blocks of different sizes located at each chromosomal end (Figs 3B, C). Nevertheless, in later meiotic stages with greater levels of chromatin condensation, such as the gonial mitotic pro-

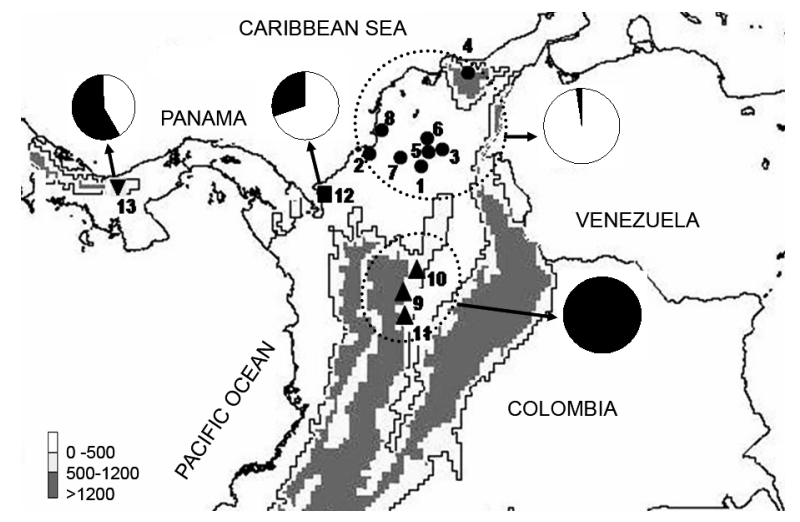

Fig. 1: location of the collection sites of Rhodnius pallescens in Colombia and Panama. Circles (•): populations from the North region; squares ( $\mathbf{\square})$ : populations from the West region; triangles $(\mathbf{\Lambda})$ : populations of the South region. For additional population data, see the corresponding number in Table. Cytotype frequency in each region is represented by Pie charts (white $=$ A cytotype; black $=$ B cytotype).

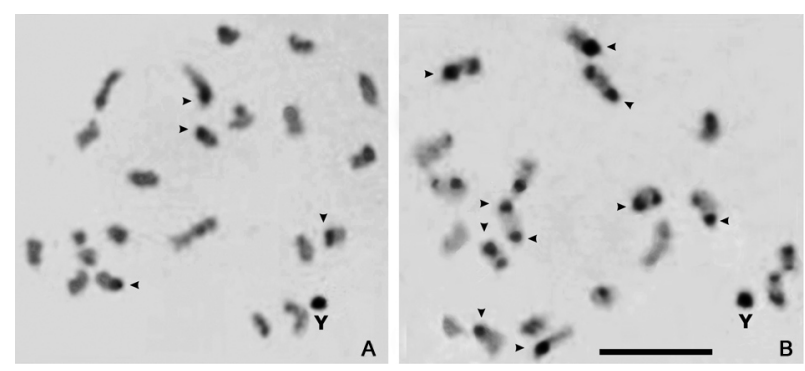

Fig. 2: Rhodnius pallescens. C-banding technique. Gonial mitosis (spermatogonial prometaphases). Males have a chromosome complement constituted by 20 autosomes plus two sex chromosomes (XY). A: A cytotype. Some autosomes (from 4 to 12) show C-blocks in one single end (arrowheads); B: B cytotype. Most of the autosomes (from 14 to 16) exhibit C-blocks in one or both chromosomal ends (arrowheads). The Y appears totally heterochromatic whereas the X chromosome appears euchromatic. Bar $=10 \mu \mathrm{m}$.

metaphase (Figs 2A, B) and/or metaphases I and II (Figs $3 \mathrm{D}, \mathrm{H}$ respectively), the $\mathrm{Y}$ chromosome appeared as completely heterochromatic. Conversely, in early prophase the $\mathrm{X}$ chromosome appeared with a dot of heterochromatin at one end (asterisk Fig. 3F), whereas in metaphases I and II it is observed as completely euchromatic (Figs 3D, H).

During metaphase I, the $\mathrm{X}$ and $\mathrm{Y}$ univalent chromosomes were located at the centre of a ring formed by the ten autosomal bivalents (Fig. 3D). At anaphase I, the chromatids of each sex chromosome separated to opposite poles (equational segregation). At metaphase II, the autosomes were again seen in the periphery of the spindle with the $\mathrm{X}$ and $\mathrm{Y}$ chromatids forming a pseudobivalent in the centre of the ring (Fig. $3 \mathrm{H}$ ). During anaphase II, the $\mathrm{X}$ and $\mathrm{Y}$ chromatids segregated to opposite poles (reductional segregation). This sequence of meiotic segregation (equational at anaphase I and reductional at anaphase II) is named "inverted meiosis" and is common in hemipteran holocentric chromosomes.

Chromosomal variation - Two chromosomal patterns or cytotypes (A and $\mathrm{B})$ were observed in individuals of $R$. pallescens according to the number, size and distribution 

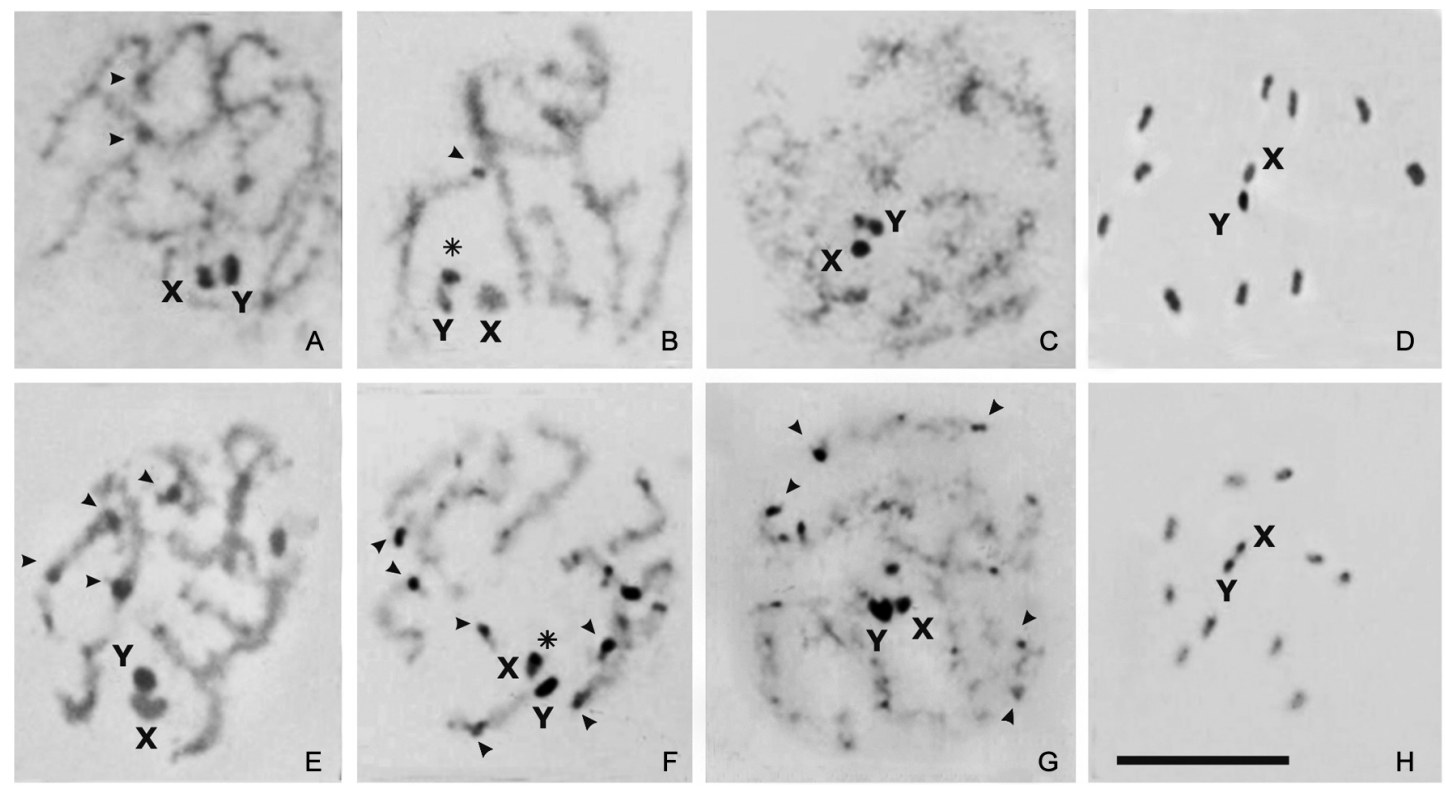

Fig. 3: Rhodnius pallescens. Male meiosis. C-banding technique. A-D: A cytotype; E-H: B cytotype. A, B: Pachytene. Few and small regions of autosomal C-heterochromatin (arrowheads) appear scattered throughout the nucleus. Both sex chromosomes (X and Y) are achiasmatic and appear close to each other but without association with the autosomes. The $\mathrm{Y}$ chromosomes can appear either as completely heterochromatic (A) or with two blocks of C-heterochromatin of different size located at each chromosomal end (asterisk B); C: diffuse. This stage is characterized by a partial decondensation of the chromatin; D: metaphase I. Bivalents adopt the typical ring configuration seen in other Hemiptera species with the univalents sex chromosomes in the centre. The Y chromosome appears totally heterochromatic and the X appears euchromatic; E: pachytene. Several blocks of autosomal heterochromatin are observed scattered throughout the nucleus (arrowheads); F: early diffuse. C-blocks of autosomal heterochromatin are clearly observed. The X chromosome has one heterochromatic block in only one chromosomal end (asterisk) whereas the Y chromosome appears totally heterochromatic; G: diffuse. The heterochromatic autosomal blocks are less clearly observed because of chromatin decondensation (arrowheads); H: metaphase II. The ten chromosomes are found in the periphery of the spindle with the X and $\mathrm{Y}$ chromosomes forming a pseudobivalent in the centre of the ring. Bar $=10 \mu \mathrm{m}$.

of C-heterochromatic regions. Cytotype A was found in specimens from the North and West regions (Fig. 1). It was characterized by the presence of some autosomes (from 4 to 12) with C-dots (small blocks) located mainly at one chromosomal end (arrowheads in Fig. 2A). During the early meiotic prophase, the autosomal heterochromatin regions appeared scattered throughout the nucleus (Figs 3A, B). Cytotype B was found in specimens from all regions, but their frequencies in the populations were very different (see discussion) (Fig. 1). This cytotype was characterized by the presence of C-blocks at one or both chromosomal ends of most autosomes (from 14 to 16) (arrowheads in Fig. 2B), were clearly observed scattered throughout the nucleus during meiotic prophase. The size of autosomal C-heterochromatic regions of B cytotype was clearly larger than the one observed in A cytotype (compare Figs 3E-F with Figs 3A-C). This difference, together with the number and distribution of C-regions, are the diagnostic characters that allow to distinguish between both cytotypes. Individuals can be easily classified analyzing first meiotic prophase; in later meiotic stages (i.e. metaphase I and II) the level of chromatin condensation is too high and the heterochromatic regions are not clearly observed (Fig. $3 \mathrm{H}$ ).

\section{DISCUSSION}

Chromosomal variability in Rhodnius - The subfamily Triatominae has a high chromosomal homogeneity. Most species have 20 autosomes with only three excep- tions: Triatoma nitida and Panstrongylus megistus (18 autosomes), and Triatoma rubrofasciata (22 autosomes). Sex chromosomes are more variable and three different mechanisms are found in the males: $\mathrm{XY}, \mathrm{X}_{1} \mathrm{X}_{2} \mathrm{Y}$ and $\mathrm{X}_{1} \mathrm{X}_{2} \mathrm{X}_{3} \mathrm{Y}$. But despite the homogeneity in chromosome number, Triatominae exhibit great variability in the banding pattern and chromosome behavior during the male meiotic process between the species and even among populations of the same species. For these reasons, cytogenetics can provide useful markers for taxonomic and population analyses (Panzera et al. 1995, 1997, Pérez et al. 2002). Heterochromatin variation studies have allowed the identification of cryptic species in Triatoma sordida (Panzera et al. 1997, Jurberg et al. 1998) and T. dimidiata (Panzera et al. 2006), as well as the detection of intra-specific variation in T. infestans (Panzera et al. 2004) and Panstrongylus geniculatus (Pérez et al. 2002). This chromosomal variation has been described mainly for species of Triatoma and Panstrongylus. Rhodnius is considered a more homogenous genus because all species described so far have the same chromosome complement $(2 \mathrm{n}=22 \mathrm{~A}+\mathrm{XY} / \mathrm{XX})$ and a similar meiotic behavior (Dujardin et al. 2002). This was confirmed by our findings in 112 individuals of $R$. pallescens that exhibited the same chromosome complement without the detection of any numerical variation. However, we detected an important variation in the amount of heterochromatin that has not been previously described for any of the 12 Rhodnius species cytologically studied so far (Dujardin 
et al. 2002). This indicates that although the chromosome number is quite stable in the genus, the karyotype can undergo important changes in its heterochromatic pattern as observed in other Triatominae species. The analysis of the variation detected in the heterochromatin led to the identification in $R$. pallescens of two distinct cytotypes (A and B) that were used as a genetic marker to analyze the variability within this species (Figs 2, 3).

Intraspecific variation of R. pallescens - The analysis of the geometric morphometry of wings and heads of six Colombian populations and one from Panama (5 of them included in this paper), revealed significant differences in size and shape among individuals from three regions: North and South of Colombia, and those from Panama (Jaramillo et al. 2002). Such morphological differences together with our analyses of the cytotype frequencies in the $R$. pallescens populations, support the existence of three population groups genetically differentiated associated with the following regions - North region: this region includes the sylvatic populations located at the Colombian Caribbean plains (Fig. 1, Table) and corresponds to the Northern distribution of the species in the country. This region is classified as tropical dry forest; it is located between 5 and $65 \mathrm{~m}$ above sea level (masl) and has a warm dry climate with an average temperature of $27^{\circ} \mathrm{C}$ (Holdridge 1967). Insects of this region present a reduced body size and significant differences in wing and head shape (Jaramillo et al. 2002). All individuals analyzed (47) except one, presented small amount of autosomal heterochromatin (A cytotype) (Figs 1, 2A, 3A-D). South region: this region includes the sylvatic populations located at the inter-Andean valleys of the eastern slope of the Colombian central cordillera and corresponds to the Southern distribution of the species (Fig. 1, Table). This region is classified as tropical humid forest and it is located over the 390 masl and has average temperatures between $18^{\circ} \mathrm{C}$ and $23^{\circ} \mathrm{C}$ (Holdridge 1967). Insects of this region present a larger body size, and more autosomal heterochromatin. All individuals analyzed from this region (24) showed the B cytotype (Figs 2B, 3E-H). West region: this region includes: a sylvatic Colombian population from Necoclí (coastal town at the Gulf of Urabá) near the border with Panama, and a Santa Fe population (domestic and sylvatic individuals) from the northwest of Panama (Fig. 1, Table). These two populations are also classified as tropical humid forest (Holdridge 1967) but the temperature and the altitude are quite different. Altitude of Necoclí is 9 masl with an average temperature of $27^{\circ} \mathrm{C}$, whereas the altitude of Santa Fe is between 500 and 900 masl with an average temperature of $24^{\circ} \mathrm{C}$. Both A and B cytotypes were detected in the two localities but with different frequencies. In the Santa Fe population, $71 \%$ of individuals (22/31) displayed the B cytotype; in the Necoclí population only $30 \%$ of individuals (3/10) showed it (Fig. 1). According with our chromosomal and morphometric data (Jaramillo et al. 2002), the populations of this region appears as a heterogeneous mixture of Northern and Southern forms. Two alternative hypotheses can be proposed to explain the observed pattern of variation encountered in the West region. Firstly, this region is a hybrid zone between the North and South ancient populations of Colombia. Secondly, the West region constitute the center of dispersion of the species towards the North and South of Colombia. Future analyses of Costa Rica and Nicaragua populations and more localities from Panama will allow testing these two alternative explanations and help to understand the historical process of dispersion of this species.

In conclusion, this work demonstrates for the first time in the genus Rhodnius an important chromosomal variation within $R$. pallescens that could be related with the ecological and geographic origin of the populations and corresponds with the morphometric variation previously described.

Additionally, the cytogenetic analyses of the species closely related with $R$. pallescens, such as Rhodnius colombiensis and Rhodnius ecuadoriensis (which integrate

TABLE

Origin of the samples, ecotopes and sample size ordered by geographic regions

\begin{tabular}{|c|c|c|c|c|c|c|}
\hline \multirow[b]{2}{*}{ Country } & \multirow[b]{2}{*}{ Region } & \multirow[b]{2}{*}{ State } & \multirow[b]{2}{*}{ Municipality / Locality } & \multirow[b]{2}{*}{ Ecotope } & \multicolumn{2}{|c|}{$\mathrm{n}$} \\
\hline & & & & & $\begin{array}{c}\text { Natural } \\
\text { population }\end{array}$ & Colony \\
\hline Colombia & North & Bolívar & Mompós (1) & Palm & 3 & - \\
\hline Colombia & North & Córdoba & San Bernardo del Viento (2) & Palm & 4 & - \\
\hline Colombia & North & Magdalena & Guamal (3) & Palm & - & 3 \\
\hline Colombia & North & Magdalena & Mendihuaca (4) & Palm & - & 2 \\
\hline Colombia & North & Magdalena & San Sebastián(5) & Palm & 26 & - \\
\hline Colombia & North & Magdalena & San Zenón (6) & Palm & - & 2 \\
\hline Colombia & North & Sucre & Galeras (7) & Palm & - & 3 \\
\hline Colombia & North & Sucre & San Onofre (8) & Palm & - & 4 \\
\hline Colombia & South & Antioquia & San Carlos (9) & Palm & - & 4 \\
\hline Colombia & South & Antioquia & Vegachí (10) & Palm & 5 & - \\
\hline Colombia & South & Caldas & Norcasia (11) & Palm & 6 & 9 \\
\hline Colombia & West & Antioquia & Necoclí (12) & Palm & 10 & - \\
\hline Panama & West & Veraguas & Santa Fé (13) & Palm \& Peridomestic & 31 & - \\
\hline
\end{tabular}

Numbers in parenthesis refer to geographic location indicated in Fig. 1. 
a monophyletic clade denominated pallescens group or Pacific Rhodnius lineage), would help to understand the taxonomy and genetic evolution in this group of species (Abad-Franch \& Monteiro 2007). Analyses of mitochondrial cytochrome b suggest that $R$. colombiensis would be representing a race or subspecies or a very recent divergence from $R$. pallescens (Abad-Franch \& Monteiro 2005). Cytogenetic analyses in experimental hybrids among these species could also provide some clues about the origin and divergence of this taxonomic group.

\section{ACKNOWLEDGEMENTS}

To CJ Schofield, F Abad-Franch for critical reading of this manuscript.

\section{REFERENCES}

Abad-Franch F 2003. The ecology and genetics of Chagas disease vectors in Ecuador, with emphasis on Rhodnius ecuadoriensis (Triatominae). PhD Thesis, London School of Hygiene and Tropical Medicine, University of London, London, UK, 411 pp.

Abad-Franch F, Monteiro FA 2005. Molecular research and the control of Chagas disease vectors. An Acad Bras Cienc 77: 437-454.

Abad-Franch F, Monteiro FA 2007. Biogeography and evolution of Amazonian triatomines (Heteroptera: Reduviidae): implications for Chagas disease surveillance in humid forest ecoregions. Mem Inst Oswaldo Cruz 102 (Suppl. I): 57-70.

Calzada JE, Pineda V, Montalvo E, Alvarez D, Santamaria AM, Samudio F, Bayard V, Cáceres L, Saldaña A 2006. Human Trypanosome infection and the presence of intradomicile Rhodnius pallescens in the western border of the Panama Canal, Panama. Am J Trop Med Hyg 74: 762-765.

Christensen HA, de Vasquez AM 1981. Host feeding profiles of Rhodnius pallescens (Hemiptera: Reduviidae) in rural villages of Central Panama. Am J Trop Med Hyg 30: 278-283.

Christensen HA, Whitlaw JT, Chaniotis BN, de Vasquez AM 1980. Sylvatic hosts of Rhodnius pallescens (Hemiptera: Reduviidae) nymphs in the Panama canal zone. J Med Entomol 17:182.

de Vasquez AM, Samudio FE, Saldaña A, Paz HM, Calzada JE 2004. Eco-epidemiological aspects of Trypanosoma cruzi, Trypanosoma rangeli and their vector (Rhodnius pallescens) in Panama. Rev Inst Med Trop Sao Paulo 46: 217-222.

Dujardin JP, Schofield CJ, Panzera F 2002. Los vectores de la Enfermedad de Chagas, Academie Royale des Sciences D’Outre-Mer, Bruxelles, $189 \mathrm{pp}$.

Galvão C, Carcavallo R, Silva-Rocha DD, Jurberg J 2003. A checklist of the current valid species of the subfamily Triatominae, Jeannel, 1919 (Hemiptera, Reduviidae) and their geographical distribution, with nomenclatural and taxonomic notes. Zootaxa 202: 1-36.

Gregory TR 2005. The evolution of the genome, Elsevier, New York, $740 \mathrm{pp}$.

Harry M, Poyet G, Romaña CA, Solignac M 1998. Isolation and characterization of microsatellite markers in the bloodsucking bug Rhodnius pallescens (Heteroptera, Reduviidae). Mol Ecol 7: 1784-1786.

Holdridge LR 1967. Life zone ecology, Tropical Science Center, Costa Rica, 206 pp.

Jaramillo N, Calle D, Caro-Riaño H, Calle J, Ortega-Barría E 2002. Diferencias morfométricas asociadas a la distribución geográfica de Rhodnius pallescens provenientes de siete localidades de Colombia y Panamá. In OPS/OMS, Iniciativa de los países de Centro América para la interrupción de la transmisión vectorial y transfusional de la Enfermedad de Chagas. Taller técnico de estudio sobre Rhodnius pallescens, su vigilancia y control, Panamá, Panamá, p. 15-22.

Jaramillo N, Schofield CJ, Gorla D, Caro-Riaño H, Moreno J, Mejía E, Dujardin JP 2000. The role of Rhodnius pallescens a vector of Chagas disease in Colombia and Panama. Res Rev Parasitol 60: 75-82.

Jurberg J, Galvão C, Lent H 1998. Revalidaçao de Triatoma garciabesi Carcavallo, Cichero, Martínez, Prosen \& Ronderos (1967) (Hemiptera -Reduviidae). Entomol Vect 5: 107-122.

López G, Moreno J 1995. Genetic variability and differentiation between populations of Rhodnius prolixus and $R$. pallescens, vectors of Chagas' disease in Colombia. Mem Inst Oswaldo Cruz 90: 353-357.

Marín RE, Vargas M 1986. Rhodnius pallescens (Hemiptera: Reduviidae) in Costa Rica. J Med Entomol 23: 333.

Morel CM, Lazdins J 2003. Chagas disease. Nat Rev Microbiol 1: 14-15.

Panzera F, Dujardin JP, Nicolini P, Caraccio M, Rose V, Téllez T, Bermúdez H, Bargues M, Mas-Coma S, O'Connor J, Pérez R 2004. Genomic Changes of Chagas Disease Vector, South America. Emerg Infect Dis 10: 438-446.

Panzera F, Ferrandis I, Ramsey J, Ordóñez R, Salazar-Schettino PM, Cabrera M, Monroy MC, Bargues MD, Mas-Coma S, O'Connor JE, Angulo VM, Jaramillo N, Cordón-Rosales C, Gómez D, Pérez R 2006. Chromosomal variation and genome size support existence of cryptic species of Triatoma dimidiata with different epidemiological importance as Chagas disease vectors. Trop Med Int Health 11: 1092-1103.

Panzera F, Hornos S, Pereira J, Cestau R, Canale D, Diotaiuti L, Dujardin JP, Pérez R 1997. Genetic variability and geographic differentiation among three species of Triatomine bugs (HemipteraReduviidae). Am J Trop Med Hyg 57: 732-739.

Panzera F, Pérez R, Hornos S, Panzera Y, Alvarez F, Scvortzoff E, Salvatella R 1995. Karyotype evolution in holocentric chromosomes of three related species of triatomines (Hemiptera- Reduviidae). Chromosome Res 3: 143-150.

Panzera F, Pérez R, Hornos S, Panzera Y, Cestau R, Delgado V, Nicolini P 1996. Chromosome numbers in the Triatominae (HemipteraReduviidae): a Review. Mem Inst Oswaldo Cruz 91: 515-518.

Panzera F, Scvortzoff E, Pérez R, Panzera Y, Hornos S, Cestau R, Nicolini P, Delgado V, Alvarez F, Mazzella MC, Cossio G, Martinez M, Salvatella R 1998. Cytogenetics of Triatomines. In RU Carcavallo, I Galíndez-Girón, J Jurberg, H Lent (eds), Atlas of Chagas Disease Vectors in the Americas, Fiocruz, Rio de Janeiro, Vol II, p. 621-664.

Pérez R, Hernández M, Caraccio M, Rose V, Valente SA, Valente VC, Moreno J, Angulo V, Ramírez CM, Roldán J, Vargas F, Wolff M, Panzera F 2002. Chromosomal evolution trends of the genus Panstrongylus (Hemiptera, Reduviidae), vectors of Chagas disease. Infect Genet Evol 2: 47-56.

Pérez R, Panzera F, Page J, Suja J, Rufas J 1997. Meiotic behaviour of holocentric chromosomes: orientation and segregation of autosomes in Triatoma infestans (Heteroptera). Chromosome Res 5: 47-56.

Ponce C 2007. Current situation of Chagas disease in Central America. Mem Inst Oswaldo Cruz 102 (Suppl. I): 41-44.

Ramírez-Pérez J 1987. Revisión de los triatominos (Hemiptera, Reduviidae) en Venezuela. Bol Dir Malariol San Amb 27: 118-146.

Zeledón R, Marín F, Calvo N, Lugo E, Valle S 2006. Distribution and ecological aspects of Rhodnius pallescens in Costa Rica and Nicaragua and their epidemiological implications. Mem Inst Oswaldo Cruz 101: 75-79. 